2017-06-01

Revisiting Connell: Competition but not as we know it.

\title{
Gordon, J
}

http://hdl.handle.net/10026.1/9395

10.1017/S0025315417000789

Journal of the Marine Biological Association of the United Kingdom

Cambridge University Press (CUP)

All content in PEARL is protected by copyright law. Author manuscripts are made available in accordance with publisher policies. Please cite only the published version using the details provided on the item record or document. In the absence of an open licence (e.g. Creative Commons), permissions for further reuse of content should be sought from the publisher or author. 
Title: Revisiting Connell: Competition but not as we know it.

Authors: Jenna M. Gordon ${ }^{1}$ and Antony M. Knights ${ }^{1 *}$

Affiliations: ${ }^{1}$ Marine Biology and Ecology Research Centre, School of Marine Science and Engineering, Plymouth University, The Davy Building, Drake Circus, Plymouth, PL4 8AA, UK.

*Corresponding author: antony.knights@plymouth.ac.uk

Running head: Intra and interspecific competition

\section{Abstract}

Space is one of the primary limiting resources for organisms on the intertidal rocky shore. This paper examined the effect of reduced density on key traits (mortality and growth) on the intertidal barnacles, Chthamalus montagui and Semibalanus balanoides, on the mid-shore in Plymouth, UK. Intra- and interspecific treatments comprising of $C$. montagui and S. balanoides were manipulated to reduce densities at two similar sites. Changes in mortality and operculum growth were assessed over an 8-week period using digital photography. Covariates of growth included nearest neighbour distance, competition between closest pairs and initial size. Conflicting patterns were observed when comparing growth rates between treatments and sites. At Site 1, interspecific treatments had a lower growth rate than intraspecific treatments, whereas at Site 2, interspecific growth rates were higher. ANCOVA showed that nearest neighbour distance had no significant effect on growth, but when comparing differences in growth of closest neighbouring pairs, $C$. montagui treatment showed evidence of competition whereas S. balanoides did not. ANCOVA analysis indicated no difference in growth between each outcome of pair competition, suggesting winners are initially bigger than losers. Comparisons of mortality between treatments indicated mortality over time with no significant differences observed between treatments, but response surface methodology (RSM) revealed no effects of competition on mortality of S. balanoides, but negative effects of both intra- and interspecific competition on C. montagui survivorship. Examination of natural populations of barnacles in the mid-shore indicated there was strong spatial variation in growth rates, perhaps driven by small-scale differences within sites.

Keywords: Barnacles; rocky shore; competition; growth; nearest neighbour distance; coexistence; rsm. 

Intra and Interspecific competition

\section{INTRODUCTION}

The effect of competition on natural populations and community dynamics has long been of interest to ecologists (Connell, 1961a,b; Tilman, 1982; Strong et al. 1984), especially the role of intraspecific and interspecific resource competition as determining factors of the structure of both terrestrial and marine populations (Hart \& Marshall, 2009; Caro et al. 2011; Shinen \& Navarrete, 2014).

Competition acts as an important feedback loop that controls population density and growth rate of the population and individuals (Begon et al. 2006). Intraspecific competition between individuals of the same species commonly leads to mortality when the resources needed to sustain them, such as food and space, become limiting (Moore, 1935; Hixon et al. 2002; Begon et al. 2006; Knights et al. 2010). This mechanism can be described by a logistic growth model which describes the negative effect of population size on growth rate until the carrying capacity is reached (birth rate equals death rate) and resources are no longer limited (Hixon et al. 2002; Neal, 2004). While changes in population size is the emergent result, intraspecific competition may in fact alter survivorship at the scale of the individual rather than a the population level, for example, as neighbouring individuals compete for a resource (Begon et al. 2006) reducing their growth and size (Hixon et al. 2002).

In addition to intraspecific competition, population size has also been shown to be dependent on interspecific interactions. The Lotka-Volterra model (Lotka, 1925; Volterra, 1926) states when two species occur together, the growth rates of both species are affected by the presence of each other (sensu 'interference competition', Neal, 2004) as a result of direct competition for the same resource which affects their growth or survival (Reece et al. 2011; Feldhamer et al. 2007). This can affect the distribution and abundance of different species in natural communities. Gause (1934) used laboratory experiments to observe resource competition between two closely related species, namely Paramecium caudatum and Stylonychia mytilus. When grown separately, each population grew rapidly before reaching asymptote at their carrying capacity $(k)$, yet when both species co-occurred, growth rates were reduced and the carrying capacity was lower. Moreover, S. mytilus appeared to partially outcompete $P$. caudatum, evident as greater reductions in the growth of $P$. caudatum than S. mytilus.

A comparison of the relative strengths of intra- and interspecific competition provides an indication of how species may coexist. The Lotka-Volterra model (Lotka, 1925; Volterra, 1926) suggests that species co-exist when intraspecific competition is stronger than interspecific competition (Connell, 1983; Ying et al. 2014); the competitively superior species is 'self-limited' by competition between individuals below a density threshold that is necessary to eliminate the other species (Connell, 1983). If the competitively superior species is not 'self-limited', then the weaker competitor may be eliminated unless external sources of mortality, such as predation or disturbance, limit the population of the superior species (Shinen \& 
Intra and Interspecific competition

Navarrete, 2014). While a well-established principle, recent studies have suggested that species are not 'coexisting' per se, but instead a species is slowly driving another to extinction (Siepielski \& McPeek 2010; Shinen \& Navarrete, 2014). Nonetheless, the relative strength of competition is important to determine if we are to predict the possibility of co-existence between species and understand changes in the density of competing species (Connell, 1983).

Barnacles have long been used to test hypotheses of intra- and interspecific competition (e.g. Connell, 1961a,b; Wethey, 1983; Jenkins et al. 2008) and have been shown to demonstrate both intra- and interspecifically by crushing or overgrowing neighbours (Connell, 1961a,b; Wethey, 1983; Jenkins et al. 2008). In intertidal systems, barnacles are excluded from higher regions of the shore by physical stress (e.g. desiccation) and reduced in number on lower shore heights by biological control (e.g. predation and competition). Their small size, dense concentrations and intertidal location make barnacles an ideal model organism for manipulation in field experiments (Leslie, 2005; Lopez et al. 2014). For instance, the survival of individuals can be determined accurately by simply mapping the position of all the members of a population and then following the same individuals by regular censuses (Connell, 1961b).

Space is one of the primary limiting resources for barnacles on the intertidal rocky shore (Connell, 1961a,b; Leslie, 2005). At high densities, intraspecific competition for space may negatively affect survival, cause changes in growth rates, and reduce reproductive activity (Barnes \& Powell, 1950; Lopez et al. 2014) and success (Hansson et al. 2003). In contrast, high densities have been reported to facilitate survival by buffering individuals from interspecific competitive pressures, consumers, physical disturbance and physiological distress (Bertness, 1989; Leslie, 2005). It is suggested that barnacles in dense aggregations grow more slowly than adjacent isolated individuals as food in the water flowing over the surface is shared among more individuals (Moore, 1935).

In a seminal study by Connell (1961a), it was found that barnacles within the mid-intertidal zone undergo significant interspecific competition. Undertaken on the Isle of Cumbrae in the Firth of Clyde, Connell demonstrated interspecific competition between two co-existing species, Chthamalus stellatus (now recognised as Chthamalus montagui and referred to as C. montagui herein, see Southward 1976) and Semibalanus balanoides. Chthamalus montagui generally occurred above S. balanoides and was shown to be able to settle lower on the shore, but was unable to survive as a result of being eliminated by $S$. balanoides over a 1-yr period. Connell argued that the short supply of a common resource caused the exclusion of $C$. montagui as space for attachment and growth was limited, and the poor survival of $C$. montagui in the lower shore was as a result being outcompeted by the faster growing species, $S$. balanoides (Connell, 1961a). 
Intra and Interspecific competition

This paper revisits Connell's study (1961a), re-testing his assumptions of intra- and interspecific competition by way of manipulated densities and combinations of $S$. balanoides and $C$. montagui. The study aims to determine whether (1) growth rates vary between intra- and interspecific treatments, and (2) if survival rate varies between intra- and interspecific treatments over time. Small-scale effects on growth between closely interacting (neighbouring) individuals are also tested.

\section{MATERIALS AND METHODS}

The study was carried out at Mount Batten, Plymouth, UK (Fig. 1) between September and December 2014. Mount Batten is a headland of limestone protruding into Plymouth Sound (see Knights et al. 2016 for description of the area). Two sites on the shore were identified and defined as limestone rock surfaces of similar aspect, gradient, tidal exposure and orientation (approx. south-west facing; see Figure 1 and www.EMODnet.eu for more information) where Semibalanus balanoides and Chthamalus montagui are locally abundant and coexist in the mid-shore. Locations were at the same tidal height and separated by $>50 \mathrm{~m}$. The study area was intentionally limited in order to reduce variability caused by differences in tidal exposure, salinity, temperature and light (Connell, 1961b).

To test for evidence and strength of intraspecific and interspecific competition in CM and SB, three treatments were established in areas characterised by $100 \%$ cover of adult barnacles. Intraspecific treatment patches contained either SB or CM, and interspecific (mixed) treatment patches contained both species. Patches were $5 \times 5 \mathrm{~cm}$ and located randomly within the mid-shore (determined using tide-tables) where both species are roughly equally abundant. The location of each patch was recorded using GPS (Garmin eTrex10, USA) and barnacles were removed from each patch using forceps to manipulate the density and occurrence of species within each patch (Fig. 2B and D) to allow a response surface experimental design to be used (see Inouye 2001) to test hypotheses about competition. The area around each $5 \mathrm{~cm}^{2}$ patch was cleared of all barnacles using a paint scraper to reduce the likelihood of edge effects (Volkenborn et al. 2007). Each quadrat ( $\mathrm{N}=30$ per site) was photographed (Panasonic DMC-FS16) prior to the removal of any barnacles, following manipulation at Time 0 and subsequently at 2, 4, 6 and 8-wk postmanipulation. Photographs were used to calculate density (and therefore mortality) and to estimate individual growth over time.

\section{Estimates of growth rate by species and treatment}

Growth was measured as the change in the length of the operculum over time (Wethey, 1983; Jenkins et al. 2008, Burrows et al. 2010), rather than the total length of the barnacle (rostro-carinal) as this metric can be severely affected by crowding, as well as other micro-topographical features of the rock surface. Operculum length of individual barnacles was measured using a photograph (e.g. Fig. 2B) that had been scaled in the image analysis programme, ImageJ (Schneider et al. 2012), and individuals geo-referenced 
Intra and Interspecific competition

allowing their growth to be tracked over time. Average growth rate (per species and per 2-wk period) was calculated for each patch and treatment type.

\section{Mortality of barnacles}

Barnacle mortality was measured using images from Time-0 and after 8-wk. Images of patches were overlaid with one-another so that individual barnacles could firstly be identified, speciated (in mixed patches) and a binary code applied to whether they were dead (0) or alive (1) after 8-wk. Individuals were identified as dead by the absence of opercular plates. These data were then used to calculate proportional mortality of each species in each patch.

\section{Growth and distance from a neighbour}

Photographs were also used to calculate the nearest neighbour distances (NND) of all barnacles in a patch. Images were imported in ArcGIS (Arclnfo 10.2.2), georeferenced and a point applied to the centre of each barnacle in an image. The ordinal distance between the centre of all barnacles were calculated using the spatial analysis toolkit (nearest neighbour tool) and NNDs used as a covariate to test the hypothesis that shorter NNDs would lead to a reduction in operculum growth as a result of competition.

Evidence of 'winners' and 'losers' in intraspecific patches

To determine if small-scale intraspecific competition occurs between barnacles in close proximity to each other, barnacles closest to each other (based on NND) were paired to test if either individual was outcompeting its 'pair' (measured as a difference in growth rate). Individuals were classified as the 'winner' and 'loser' based on growth rate differences; the individual that grew more was the 'winner'. When no evidence of growth rate differences was seen (i.e. equal growth in paired individuals), the contest was considered a 'draw'. The operculum length of each barnacle at the start of the experiment was also used as a covariate to account for potential differences in growth rate based on starting size (Moore, 1939).

\section{Statistical Analysis}

Growth rates were compared using an orthogonal 2-factor ANOVA with the factors: (1) Site (2 levels, random), and (2) Treatment (3 levels: CM only, SB only, CM+SB (mixed)). The outcome of paired competitions as determined by growth rate was also tested using 2-factor ANOVA with the factors: (1) Outcome (3 levels: Win, Lose or Draw), and (2) Treatment (2 levels: CM only, SB only). Significant differences between means were compared using post-hoc pairwise comparisons (Tukey HSD, 'car' 171 package). 
Intra and Interspecific competition

covariate (NND in $\mathrm{mm}$ ). Step-wise model simplification of the maximal ANCOVA model was used to test between slope and intercept parameters for the relationship between growth and initial size (covariate) and categorical factor levels. Akaike Information Criteria (AIC) was used determine the best-fitting model (Burnham and Anderson 2007).

Change in barnacle density and mortality over 8 wk between treatments was compared using linear mixed effects models (Imer) with an auto-regression (1) correlation structure to account for possible temporal autocorrelation effects. Local regression (loess) was used to describe change in average density over time between treatments. For all analyses above, data were tested for residual normality and homoscedasticity prior to statistical analyses, and in cases of significance $(p<0.05)$, data were log transformed. Multicollinearity was examined using the variance inflation factor (VIF), values of which were $<10$, and therefore unlikely to affect regression outcomes (O'Brien 2007).

To test for evidence of intraspecific and interspecific competition, mortality within plots was compared using a response surface method (after Box et al. 2005; see Inouye 2001, Lenth 2016 and Fig 7D for mixture details) and ANOVA tests. The effect of CM and SB density on mortality of CM and SB was modelled using first-order polynomial regression models and ANOVA tests, $R^{2}$ for goodness-of-fit and plotted using perspective plots.

All analyses were performed using the software $R$ (R Core Team, 2016) using the R packages, 'graphics', 'Ime4' (Bates et al. 2015) and 'rsm' (Lenth 2009).

\section{RESULTS}

Variation of operculum growth in relation to treatment $(\mathrm{Tr})$ and site (Si)

There was marked spatial variation in operculum growth rates among treatments between sites (Table 1, Si $x \operatorname{Tr}, p<0.0001$ ). In intraspecific treatments, CM grew $\sim 16 \%$ more at Site 2 than Site 1 , whereas for SB, the pattern was reversed with SB growing $\sim 21 \%$ more at Site 1 than 2 (Figure 3). In the interspecific treatment containing both barnacle species, average growth was significantly higher $(\sim 44 \%)$ at Site 2 than Site 1 . A comparison of the three treatments across sites indicated little variation in operculum growth at Site 1 irrespective of treatment, whereas at Site 2, growth was highest in the $\mathrm{CM}+\mathrm{SB}$ and $\mathrm{CM}$ only treatments, and lowest in the SB only treatment (Figure 3).

\section{Variation in operculum growth in relation to nearest neighbour distance}

When data were combined within a single analysis without consideration of barnacle 'pairings', there was no effect of nearest neighbour distance on the operculum growth of an individual in any of the treatments (Table $2, N N D, p>0.01)$. Operculum growth was highly variable, especially when NNDs were short $(<5 \mathrm{~mm})$ 
Intra and Interspecific competition

211 (Figure 4) and individuals located further away from a neighbour (i.e. large NND) showed no significant

212 increase in growth in comparison to those with barnacles closer to them.

213

214

215

216

217

218

219

220

221

222

223

224

However, when barnacles were 'paired' to those closest to each other and classified as either a 'winner', 'loser' or 'draw' based on their growth after 8-wk, ANOVA indicated significant differences in growth between treatment (Table 3, Outcome x Treatment, $p<0.05$ ). In general, losers grew $60 \%$ less than individuals classified as winners. Post-hoc comparisons revealed clear differences in growth between winners, losers and drawing individuals within $\mathrm{CM}$ and SB treatments (Figure 5). In the CM treatment, winners grew significantly more than individuals who lost, but losers also grew more than those paired individuals who drew. In the SB treatment, winners grew significantly more than individuals who lost or drew, but there were no significant differences between losing individuals and drawing pairs (Figure 5).

\section{Effect of operculum size on growth over time}

Growth was dependent on the initial size of the barnacle (at Time-0) and the outcome of the 'competition' between paired individuals (Table $4, p<0.01$ ). The ANCOVA revealed that the slopes were parallel but the intercepts (starting body size) were significantly different, indicating that the initial operculum size affected the outcome of the contest i.e. a larger individual was more likely to 'win' a contest (Figure 6). There was a negative relationship between growth and initial operculum size suggesting smaller individuals had a greater scope-for-growth than larger individuals.

\section{Variation in survival of barnacles in relation to time (Ti) and treatment (Tr)}

There was a significant decrease in survival over time (Table 5, $\mathrm{Ti}, \mathrm{p}<0.001$ ). Overall there was a $57 \%$ decrease in total barnacle survival after 8-wk, although densities approached asymptote after 4-wk suggesting a period of rapid early mortality of individuals $(0-<4-w k)$ followed by relatively little mortality (Figure 7). There was no significant difference in survival between the three treatments over time (Table 5, Figure 7).

\section{Response Surface Methodology (RSM) for testing competition}

Fitting a response surface model indicated that in mixed plots, the density of both CM and SB had a significant effect on the mortality of CM (Table 6, $p<0.05$ ). Mortality was highest when (i) CM occurred at intermediate densities ( 40 individuals per $25 \mathrm{~cm}^{2}$ ) in conjunction with high ( 60 individuals per $25 \mathrm{~cm}^{2}$ ) densities of SB, or (ii) when densities of CM were low and SB were absent (Table 6, Figure 8). In contrast, model reduction revealed no significant effect of CM density or SB density on SB mortality $\left(F_{1,13}=0.5983\right.$, $p=0.45$ ) suggesting no negative effects of intra- or interspecific competition on SB at the patch scale. 
Intra and Interspecific competition

\section{DISCUSSION}

The results of this study demonstrate that Semibalanus balanoides and Chthamalus montagui show strong spatial variation in operculum growth in areas where their distributions overlap in their intertidal. The composition of the patch - either a single species (CM or SB only) or a mixture of both species $(\mathrm{CM}+\mathrm{SB})$ had a greater influence on growth than density. A comparison of the growth of all individuals in a patch with consideration of distance between individuals (nearest neighbour distance) suggested little or no competition was occurring between individuals, but comparisons at smaller spatial scales focusing on pairs of individuals neighbouring each other revealed clear 'winners' and 'losers' in terms of individual growth with few 'draws'. An individual with a larger operculum from the outset of a paired competition tended to result in that individual 'winning' the growth competition, although larger individuals tended to grow less than smaller conspecifics. Comparing mortality rates at the patch level using a surface response method suggests that $\mathrm{CM}$ are undergoing competition, both with conspecifics and SB, whereas SB show no evidence of mortality related to competition.

Connell (1961a) investigated growth rates of intertidal barnacles, discovering growth rates of S. balanoides were greater than that of Chthamalus montagui. While direct interactions between S. balanoides and $C$. montagui have not been investigated, based on Connell's findings it was predicted that $S$. balanoides would have a higher operculum growth rate than $C$. montagui when co-existing. Treatments containing only a single species (CM or SB) indicated considerable variation in operculum growth depending on location. Differences in growth were not consistent across species, with growth of $C$. montagui greater at Site 2 over Site 1 , and for S. balanoides, greater at Site 1 over Site 2 . This differentiation may be due to relatively smallscale spatial variation in resource availability between sites located on Mount Batten shore. In previous studies, spatial heterogeneity of biotic and abiotic conditions that vary among-rocks within a shore has been found to influence fluctuations in population growth (Fukaya et al. 2013). This is especially important in temperate regions, where seasonal fluctuations have been shown to affect growth; in the summer, population growth rates are strongly affected by regional-scale fluctuation, whereas in winter growth is affected more by rock-scale fluctuation (Fukaya et al. 2010). Given Connell (1961a) carried out his study in spring/summer and this study undertaken in the autumn (fall), rock-scale fluctuations may have influenced the results. Lopez et al. (2010) also showed variation in morphological structures (e.g. filtration and respiration) due to spatial-temporal fluctuations in biotic and abiotic factors including density and wave exposure. Such variation may also account for some of the variation in individual growth rates and explain the differences here.

Shinen and Navarrete (2014) indicated that in the two barnacle species, Notochthamalus scabrosus and Jehlius cirratus, growth rates were largely consistent and independent of occurring together or separately. Certainly, in this study, growth rates of $C$. montagui at Site 1 was largely the same irrespective of it 
Intra and Interspecific competition

occurred in isolation or in combination with S. balanoides. In contrast, the growth of S. balanoides was marginally greater when occurring in isolation than when occurring with C. montagui although clear significant differences could not determined. Connell (1961a) reported differences in growth between intraspecific and interspecific treatments, where he showed the average growth of $C$. montagui was higher when independent of S. balanoides (Connell, 1961a). In contrast, at Site 2 the average growth of individuals in the interspecific treatment $(\mathrm{CM}+\mathrm{SB})$ was higher than when $\mathrm{S}$. balanoides occurred on its own and the growth of $C$. montagui occurring in isolation marginally lower, contradicting Connell's findings (1961a). Location, even at relatively small spatial scales, appears to play an important role in the effect of interspecific interactions (Sandford \& Menge, 2001). Thus, the experimental area - a unique shore on the Isle of Cumbrae in the Firth of Clyde, Scotland - and level of replication used in Connell's study (1961a) may therefore be less representative of general interaction strength implications than previously thought. The mechanisms that alter growth rates in interspecific treatments remain unclear, but it is suspected that differences in microhabitats, which vary greatly in their degree of physical stress, may be related to differences of growth as this environmental heterogeneity creates distinct selection regimes (Schmidt \& Rand, 1999; Schmidt et al. 2015) and this should be explored further to tease apart differences.

Many studies have shown high densities of organisms can negatively affect growth if resources are limited due to increased competition (Barnes \& Powell, 1950; Connell, 1961a,b; Leslie, 2005; Lopez et al. 2014). Here, including nearest neighbour distance (NND) between all individuals had no effect on growth (although growth was highly variable) suggesting that resources were not limited in this instance at scale of a patch to the extent that competition was reduced and both species were able to co-exist (Gerwing et al. 2016). Higher densities of organisms has been shown to facilitate growth as the complex structure that is formed (e.g. mussel hummocks) can buffer individuals from physical disturbance, consumers and physiological stress (Bertness, 1989; Leslie, 2005) and elevate individuals exposing them to higher particle fluxes (Bertness et al. 1998). Our results for C. montagui indicate some support for these mechanisms, with individuals on average exhibiting increased growth in areas of higher density.

The relative strength (importance) of intraspecific and interspecific competition has long been debated, with intraspecific competition often implicated as the main driver of negative effects (e.g. reductions in growth) through competition for resources between closely matched individuals (Moore, 1935; Hixon et al. 2002; Begon et al. 2006). Here, there were significant differences in growth between neighbouring pairs of C. montagui and S. balanoides indicating clear winners and losers at small-spatial scales. As early as 1939, Moore demonstrated that the initial size of a S. balanoides could influence its growth. Here, initial operculum size was a good predictor of whether an individual would win, lose or draw a contest, with larger individuals tending to win a contest over smaller counterparts. There was also a difference in growth 
Intra and Interspecific competition

potential, with individuals with a smaller operculum size growing more than larger conspecifics within contest categories.

Differentiation between winners and losers helps to partition much of the variability in growth at the patch level. Interestingly, while there were relatively few 'drawn' contests, where they occurred, growth in $C$. montagui was greatly reduced in drawn contests such that growth was lower than the 'loser' in a contest where there was a clear winner and loser. In S. balanoides, growth of the 'loser' or those featuring in a 'drawn' contest exhibited similar but reduced growth in comparison to a 'winning' individual. These results suggest that competition occurs at the spatial scale of individuals, rather than at the patch level, requiring comparisons to be made at the scale of individuals if we are to be able to detect the effect of competition on patch dynamics. Given the differences in growth of $C$. montagui and S. balanoides as a result of individual contests suggests that there may be differences, perhaps in the morphology or physiological requirements of the two species, that alters the strength of mechanisms such as interference competition (Shinen and Navarrete, 2010) allowing S. balanoides to be more successful than C. montagui when occurring in close proximity with conspecifics. This explanation is supported by the comparison of mortality rates between species, which show negative effects of competition on CM, but not SB.

Interspecific competition can also have a negative effect on a species survival (Connell, 1961a; Wethey, 1983; Jenkins et al. 2008). Connell (1961a) showed direct competition between S. balanoides and C. montagui and indicated crowding was an important cause of death of $C$. montagui. Crowding can lead to an elongation of the calcareous and exoskeleton structures (Bertness et al, 1998; Lopez et al. 2007), especially in S. balanoides, which have been shown to grow tall, thin-walled and dependent on neighbours for structural support (Connell, 1961a). Aggregations can be extremely fragile (Bertness, 1989) such that water motion (e.g. from wave exposure) can reduce barnacle survival (Connell, 1961b; Gaylord, 1999). Reductions in density, through mechanisms such as disturbance or predation (Knights et al, 2012), can increase survival and reduce competition between or within species (Bertness, 1989; Bracewell et al, 2013). Here, no difference in the rate of survival of SB between intraspecific and interspecific treatments was found suggesting that density of individuals in interspecific plots was sufficiently low to reduce the impacts of direct competition between the two species, increasing survivorship of both species within the patch.

In summary, this study suggests small-scale spatial distribution of organisms, the density and composition of species within a patch plays an important role in determining the strength (or lack of) intraspecific and interspecific competition in intertidal communities. The results show clear variability in the outcome of contests between individuals of the same and different species related to these factors and indicates that an evaluation of the mechanism at the scale of a patch may not capture the effects of those processes 
Intra and Interspecific competition

effectively. The role of competition in the affecting the structure and functioning of intertidal shores is clearly important, however, the mechanisms may not be as generic as previously thought.

\section{ACKNOWLEDGMENTS}

We would like to thank Louis Evans and Tom Anderson for their assistance in the field and the technical support of Plymouth University. We would especially like to thank Dr Sarah Lane for valued discussions regarding animal contests.

\section{REFERENCES}

Barnes, H. and Powell, H.T. (1950) The development, general morphology and subsequent elimination of barnacle populations, Balanus crenatus and Balanus balanoides, after a heavy initial settlement. Journal of Animal Ecology 19 (2), 175-179.

Bates, D., Maechler, M., Bolker, B. and Walker, S. (2015) Fitting linear mixed-effect models using Ime4. Journal of Statistical Software 67(1), 1-48.

Begon, M., Townsend, C. and Harper, J. (2006) Ecology: From Individuals to Ecosystems. 4th edition. Oxford: Blackwell Publishing, pp.132-163.

Bertness, M.D. (1989) Intraspecific competition and facilitation in a northern acorn barnacle population. Ecology 70 (1), 257-268.

Bertness, M.D., Gains, S.D. and Yeh, S.M. (1998) Making mountains out of barnacles: The dynamics of acorn barnacle hummocking. Ecology 79 (4), 1382-1398.

Box, G.E.P, Hunter, J.S., and Hunter, W.G. (2005) Statistics for Experimenters (2nd ed.). Wiley-Interscience.

Bracewell, S.A., Robinson, L.A., Firth, L.B., Knights, A.M. (2013) Predicting free-space occupancy on novel artificial structures by an invasive intertidal barnacle using a removal experiment. Plos One 8 (9), 1-7.

Burnham, K.P. and Anderson, D.R. (2004) Multimodel inference understanding AIC and BIC in model selection. Sociological Methods \& Research 33(2), 261-304.

Burrows, M.T., Jenkins, S.R., Robb, L., Harvey, R. (2010) Spatial variation in size and density of adult and post-settlement Semibalanus balanoides: effects of oceanographic and local conditions. Mar Ecol Prog Ser $398,207-219$ 
Intra and Interspecific competition

Caro, A.U., Guiñez, R., Ortiz, V. and Castilla, J.C. (2011) Competition between a native mussel and a nonindigenous invader for primary space on intertidal rocky shores in Chile. Marine Ecology Progress Series 428 (1), 177-185.

Connell, J.H. (1961a) The influence of interspecific competition and other factors on the distribution of the barnacle Chthamalus stellatus. Ecological Society of America 42 (1), 710-723.

Connell, J.H. (1961b) Effects of competition, predation by Thais lapillus, and other factors on natural populations of the barnacle Balanus balanoides. Ecological Society of America 31 (1), 62-103.

Connell, J.H. (1983) On the prevalence and relative importance of interspecific competition: evidence from field experiment. The American Naturalist 122 (5), 661-662.

Feldhamer, G.A., Dricamer, L.C., Vessey, S.H., Merritt, J.F. and Krajewski, C. (2007) Mammalogy: Adaptation, Diversity, Ecology. Maryland: The Johns Hopkins University Press, pp. 481-482.

Fukaya, K., Okuda, T., Hori, M., Yamamoto, T., Nakaoka, M. and Noda, T. (2013) Variable processes that determine population growth and an invariant mean-variance relationship of intertidal barnacles. Ecological Society of America 4 (4), 48.

Fukaya, K., Okuda, T., Nakaoka, M., Hori, M. and Noda, T. (2010) Seasonality in the strength and spatial scale of processes determining intertidal barnacle population growth. Journal of Animal Ecology 79 (6), 1270-1279.

Gause, G.F. (1934). Experimental analysis of Vito Volterra's mathematical theory of the struggle for existence. Science 79(2036), 16-17.

Gaylord, B. (1999) Detailing agents of physical disturbance: wave-induced velocities and accelerations on a rocky shore. Journal of Experimental Marine Biology and Ecology 239 (1), 85-124.

Gerwing, T. G., Drolet, D. Hamilton, D.J. and Barbeau, M.A. (2016) Relative importance of biotic and abiotic forces on the composition and dynamics of a soft-sediment intertidal community. Plos One. 11 (1), $1-15$

Hart, S.P. and Marshall, D.J. (2009) Spatial arrangement affects population dynamics and competition independent of community composition. Ecological Society of America 90 (6), 1485-1491.

Hixon, M.A., Pacala, S.W. and Sandin, S.A. (2002) Population regulation: historical context and contemporary challenges of open vs. closed systems. Ecology 83 (6), 1490-1508. 
Intra and Interspecific competition

408

409

410

411

412

413

414

415

416

Inouye, B.D. (2001) Response surface experimental designs for investigating interspecific competition. Ecology 82, 2696-2706.

Jenkins, S.R., Murua, J. and Burrows, M.T. (2008) Temporal changes in the strength of density-dependent mortality and growth in intertidal barnacles. Journal of Animal Ecology 77 (1), 573-584.

Knights, A.M. and Walters, K. (2010) Recruit-recruit interactions, density-dependent processes and population persistence in the eastern oyster Crassostrea virginica. Marine Ecology Progress Series 404, 7990.

Knights, A.M., Firth, L.B., and Walters, K. (2012) Interactions between multiple recruitment drivers: postsettlement predation mortality overrides flow-mediated recruitment. Plos One 7(4), e35096.

Knights, A.M., Firth, L.B., Thompson, R.C., Yunnie, A.L.E., Hiscock, K., and Hawkins, S.J. (2016). Plymouth A World Harbour through the ages. Regional Studies in Marine Science. http://dx.doi.org/10.1016/j.rsma.2016.02.002.

Lenth, R.V. (2009) Response-Surface Methods in R, Using rsm. Journal of Statistical Software 32(7), 1-17.

Leslie, H.M. (2005) Positive intraspecific effects trump negative effects in high-density barnacle aggregations. Ecology 86 (10), 2716-2725.

López, B.A., Catalán, A.M., Barriga, D.A. and López, D.A. (2014) Morphological response of the exoskeleton in the intertidal barnacle Jehlius cirratus growing at different densities. Journal of Crustacean Biology 1 (1), 1-6.

López, B.A., Ramírez, R.P., Guaitro, S.Y. and López, D.A. (2010) Interspecific differences in the phenotypic plasticity of intertidal barnacles in response to habitat changes. Journal of Crustacean Biology 30 (3), $357-$ 365.

López, D.A., López, B.A., Burgosb, I.C., Arriagadac, S.E. and González, M.L. (2007) Consequences of base modification in hummocks of the barnacle Austromegabalanus psittacus. New Zealand Journal of Marine and Freshwater Research 41 (3), 291-298.

Lotka, A.J. (1925) Elements of Physical Biology. Williams and Wilkins Baltimore Company.

Menge, B.A. (1978) Predation intensity in a rocky intertidal community. Effect of an algal canopy, wave action and desiccation on predator feeding rates. Oecologia 34 (1), 17-35.

Moore, H.B. (1935) The biology of Balanus balanoides. IV. Relation to environmental factors. Journal of the Marine Biological Association of the United Kingdom 20 (2), 279-307. 
Intra and Interspecific competition

Moore, H.B. (1939) The biology of Balanus balanoides. I. Growth rate and its relation to size, season and tide level. Journal of Marine Biological Association of the United Kingdom 17 (1), 851-868.

Neal, D. (2004) Introduction to Population Biology. Cambridge: Cambridge University Press. pp. 68-70.

O'Brien, R.M. (2007) A caution regarding rules of thumb for Variance Inflation Factors. Quality \& Quantity 41(5), 673-690.

Paine, R.T., (1984) Ecological determinism in the competition for space. Ecology 65, 1339-1348.

R Development Core Team. (2012) R: A language and environment for statistical computing. Vienna, Austria. Available at: http://www.r-project.org/.

Reece, J.B., Urry, L.A., Cain, M.L., Wasserman, S.A., Minorsky, P.V. and Jackson, R.B. (2011) Campbell Biology. USA: Pearson Education. pp. 1200-1300.

Sandford, E. and Menge, B.A. (2001) Spatial and temporal variation in barnacle growth in a coastal upwelling system. Marine Ecology Progress Series 209 (1), 143-157.

Schmidt, P.S., Bertness, M.D. and Rand, D.M. (2015) Environmental heterogeneity and balancing selection in the acorn barnacle Semibalanus balanoides. The Royal Society 282 (1804), 379-383.

Schmidt, P.S. and Rand, D.M. (1999) Intertidal microhabitat and selection at MPI: interlocus contrasts in the northern acorn barnacle, Semibalanus balanoides. Evolution 53 (1), 135-146.

Schneider, C.A., Rasband, W.S. and Eliceiri, K.W. (2012) NIH Image to ImageJ: 25 years of image analysis. Nature Methods 9 (1), 671-675.

Shinen, J.L. and Navarrete, S.A. (2010) Coexistence and intertidal zonation of chthamalid barnacles along central Chile: Interference competition or a lottery for space? Journal of Experimental Marine Biology and Ecology 392, 176-187

Shinen, J.L. and Navarrete, S.A. (2014) Lottery coexistence on rocky shores: weak niche differentiation or equal competitors engaged in neutral dynamics? The American Society of Naturalists 183 (3), 342-362.

Siepielski, A.M. and McPeek, M.A. (2010) On the evidence for species coexistence: a critique of the coexistence program. Ecological Society of America 91 (11), 3153-3164.

Southward, A.J. (1976) Taxonomic status and distribution of Chthamalus stellatus (Cirripedia) in Northeast Atlantic region - with a key to common intertidal barnacles of Britain. Journal of the Marine Biological Association of the United Kingdom 56(4), 1007-1028. 
Intra and Interspecific competition

465 Strong, D.R. Simberloff, D. Abele, and L. Thistle, A. (1984) Ecological Communities: Conceptual Issues and 466 Evidence. New Jersey: Princeton University Press. pp. 201.

467 Tilman, D. (1982) Resource Competition and Community Structure. Princeton: Princeton University Press. 468 pp. 51-75.

469 Volkenborn, N., Hedtkamp, S.I.C., van Beusekom, J.E.E. and Reise, K. (2007) Effects of bioturbation and 470 bioirrigation by lugworms (Arenicola marina) on physical and chemical sediment properties and 471 implications for intertidal habitat succession. Estuarine, Coastal and Shelf Science 74 (1), $331-343$.

472 Volterra, V. (1926) Fluctuations in the abundance of a species considered mathematically. Nature 118 (1), $473 \quad 558-560$.

474 Wethey, D.S. (1983) Intrapopulation variation in growth of sessile organisms: natural populations of the 475 intertidal barnacle Balanus balanoides. Oikos 40 (1), 14-23.

476 Ying, Z., Liao, J., Wang. S., Hui, L. and Liu, Y. (2014) Species coexistence in a lattice-structured habitat: 477 effects of species dispersal and interactions. Journal of Theoretical Biology 359 (1), 184-191. 
Intra and Interspecific competition

481 Tables

482

483 Table 1. ANOVA of average growth in relation to site and treatment at Mount Batten, Plymouth, in 2014 (n $484=5)$.

485

486

Table 2. Analysis of covariance (ANCOVA) of barnacle operculum growth in relation to nearest neighbour distance and treatment ( $\mathrm{Sb}$ only; $\mathrm{Cm}$ only; $\mathrm{Sb}+\mathrm{Cm}$ ).

488

Table 3. Analysis of Variance (ANOVA) of barnacle growth in relation to outcome (win, lose, draw) and intraspecific treatments (S. balanoides and C. montagui).

491

492

Table 4. Analysis of Covariance (ANCOVA) of barnacle growth in relation to initial size and outcome (win, lose, draw).

494

Table 5. Linear mixed effects model summary testing the effect of time ( $\mathrm{Ti}$ ) and intraspecific treatment on survival.

497

498 Table 6. Response Surface Model Fitting (ANOVA) of Chthamalus montagui and Semibalanus balanoides 499 barnacle survival in mixed treatments.

500

501 
Intra and Interspecific competition

\section{List of Figures}

Figure 1. Geographical location of the study in Plymouth, UK. Inset: the intertidal rocky shore at Mount Batten $\left(50^{\circ} 21^{\prime} \mathrm{N}, 4^{\circ} 07^{\prime} \mathrm{W}\right)$.

Figure 2. Schematics and photograph of $5 \mathrm{~cm}^{2}$ manipulative treatment plots used to test for evidence of intraspecific (A; B - Chthamalus montagui only) and interspecific (C) competition and (D) the response surface experimental design with example species densities in each patch at Time- 0 as recommended by Inouye (2001).

Figure 3. Mean $( \pm S E ; n=5)$ log growth of barnacle opercula in three treatments: $C M+S B$ (mixed species plots), CM (Chthamalus montagui only) and SB (Semibalanus balanoides only) at two sites after 8-wk. Posthoc pairwise comparison results are shown as letters above columns, where different letters indicates significant differences between 'treatment $x$ site' combinations $(p<0.01)$.

Figure 4. Scatterplot of operculum growth in individual barnacles after 8-wk in relation to distance $(\mathrm{mm})$ from its nearest neighbour. Different treatment combinations are shown: Semibalanus balanoides + Chthamalus montagui (white); Chthamalus montagui only (grey); and Semibalanus balanoides only (black).

Figure 5. Growth of barnacles who 'win' (white), 'lose' (grey) or 'draw' (black) in a contest with their nearest neighbour in intraspecific competition treatments (Chthamalus montagui (CM) and Semibalanus balanoides (SB)). Post-hoc pairwise comparison outcomes are shown as letters above columns, where different letters indicates significant differences between groups $(p<0.05)$.

Figure 6. Relationship between initial operculum size $(\mathrm{mm})$ and growth after 8-wk for barnacles that 'win' (white circles, dashed line), 'lose' (grey circles, dotted line), and 'draw' (black circles, solid line). Significant regressions are shown $(p<0.05)$.

Figure 7. Panel plot showing survival over time (weeks) for each treatment combination in 10 replicate quadrats: Mixed (CM + SB), CM (Chthamalus montagui) and SB (Semibalanus balanoides). A LOESS smoother with a span of 1 was fitted to aid visual interpretation.

Figure 8. Response surface plot of Chthamalus montagui proportional mortality in $25 \mathrm{~cm}^{2}$ plots after 8 -wk. 
Intra and Interspecific competition

537

\section{TABLES}

538

Table 1. ANOVA of operculum growth $(\mathrm{mm})$ in relation to site and treatment at Mount Batten, Plymouth, in 5392014.

\begin{tabular}{lllll}
\hline Source & Df & MS & $\boldsymbol{F}$ & P \\
\hline Site (Si) & 1 & 0.03 & 2.91 & 0.089 \\
Treatment (Tr) & 2 & 0.16 & 17.21 & $<0.0001^{* * * *}$ \\
Si x Tr & 2 & 0.16 & 17.88 & $<0.0001^{* * * *}$ \\
Residual & 777 & 0.009 & & \\
\hline
\end{tabular}

540

541 Table 2. Analysis of covariance (ANCOVA) of barnacle operculum growth in relation to nearest neighbour 542 distance and treatment (SB only; CM only; $C M+S B$ ).

\begin{tabular}{lllll}
\hline Source & df & MS & F & P \\
\hline Treatment $(T r)$ & 2 & 2.944 & 3.79 & $<0.05^{*}$ \\
Nearest neighbour distance (NND) & 1 & 2.253 & 2.90 & 0.089 \\
Residual & 816 & 0.776 & & \\
\hline
\end{tabular}

543

544 Table 3. Analysis of Variance (ANOVA) of barnacle growth in relation to outcome (win, lose, draw) and 545 intraspecific treatments (SB and CM).

\begin{tabular}{lllll}
\hline Source & df & MS & $\boldsymbol{F}$ & $\mathbf{P}$ \\
\hline Outcome (Ot) & 2 & 0.5707 & 37.59 & $<0.001^{* * *}$ \\
Treatment (Tr) & 1 & 0.0465 & 3.062 & 0.0810 \\
Ot x Tr & 2 & 0.0460 & 3.028 & $<0.05^{*}$ \\
Residual & 355 & 0.0152 & & \\
\hline
\end{tabular}


Intra and Interspecific competition

550 Table 4. Analysis of Covariance (ANCOVA) of barnacle growth in relation to initial size and outcome (win, 551 lose, draw).

\begin{tabular}{lllll}
\hline Source & df & MS & $\boldsymbol{F}$ & $\mathbf{P}$ \\
\hline Outcome (Ot) & 2 & 0.56084 & 42.057 & $<0.001^{* * *}$ \\
Initial size (In) & 1 & 0.52175 & 39.126 & $<0.001^{* * *}$ \\
Residual & 455 & 0.01334 & & \\
\hline
\end{tabular}

552

553

554 Table 5. Linear mixed effects model summary testing the effect of time (Ti) and intraspecific treatment on 555 survival.

\begin{tabular}{lllll}
\hline Source & Value & Std. Error & DF & $P$ \\
\hline (Intercept) & 55.41037 & 7.15 & 135 & $<0.001 * * *$ \\
Time (Ti) & -5.27866 & 1.37 & 135 & $<0.001 * * *$ \\
Chthamalus montagui (CM) & 11.05549 & 9.52 & 135 & 0.2473 \\
Semibalanus balanoides (SB) & 1.50183 & 9.52 & 125 & 0.8748 \\
Ti $\times$ CM & 0.52012 & 1.93 & 125 & 0.7884 \\
Ti $\times$ SB & 2.25671 & 1.93 & 135 & 0.2454 \\
\hline
\end{tabular}

556

557 Table 6. Response Surface Model Fitting (ANOVA) of Chthamalus montagui and Semibalanus balanoides 558 barnacle survival in mixed treatments.

\begin{tabular}{lllll}
\hline Source & Df & MS & $\boldsymbol{F}$ & $\boldsymbol{P}$ \\
\hline Model (CM mortality) & 2 & 0.394 & 5.19 & $\mathbf{0 . 0 2 4 *}$ \\
Residual & 12 & 0.076 & & \\
Lack of fit & 12 & 0.076 & & \\
Model (SB mortality) & 2 & 0.059 & 0.65 & 0.54 \\
Residual & 12 & 0.092 & & \\
Lack of fit & 12 & 0.092 & & \\
\hline$R^{2}(\mathrm{CM})=0.38$ & & & & \\
\hline
\end{tabular}


Intra and Interspecific competition

561

562

FIGURES

563

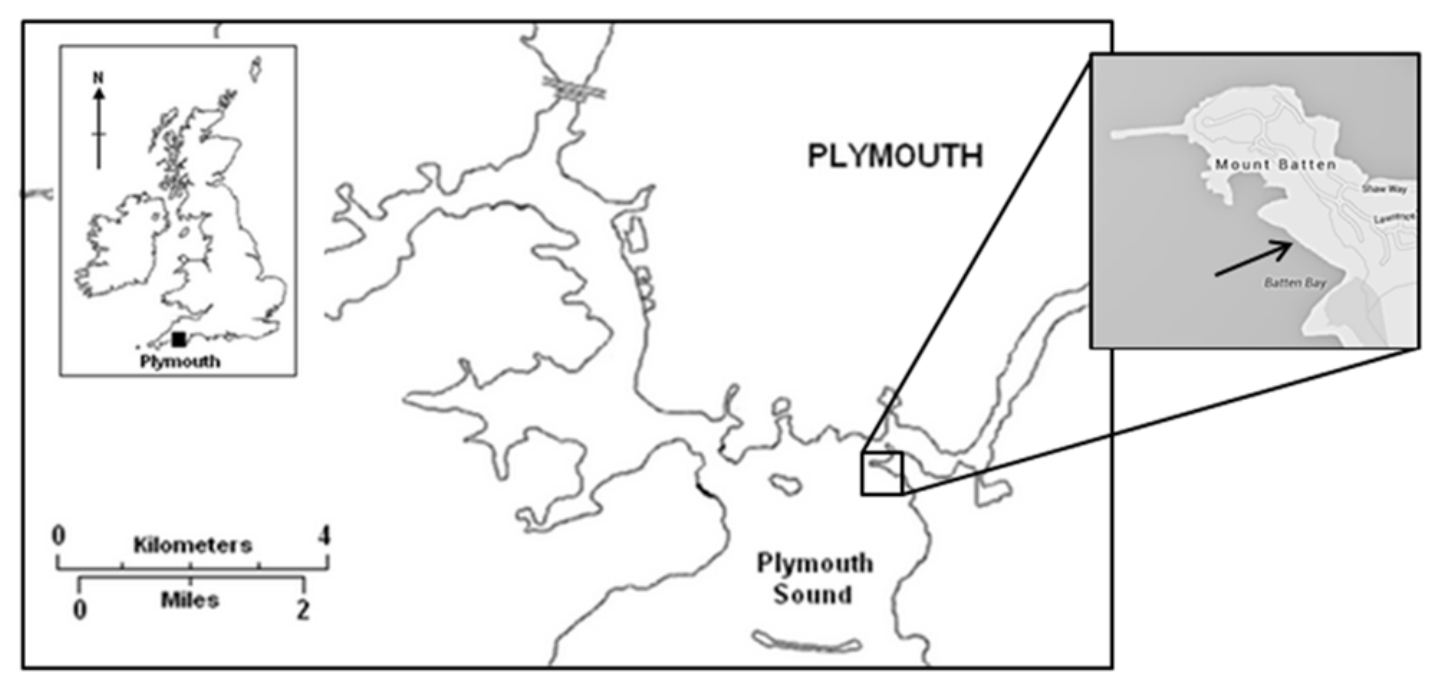

564

565

Fig. 1 
Intra and Interspecific competition

566

567
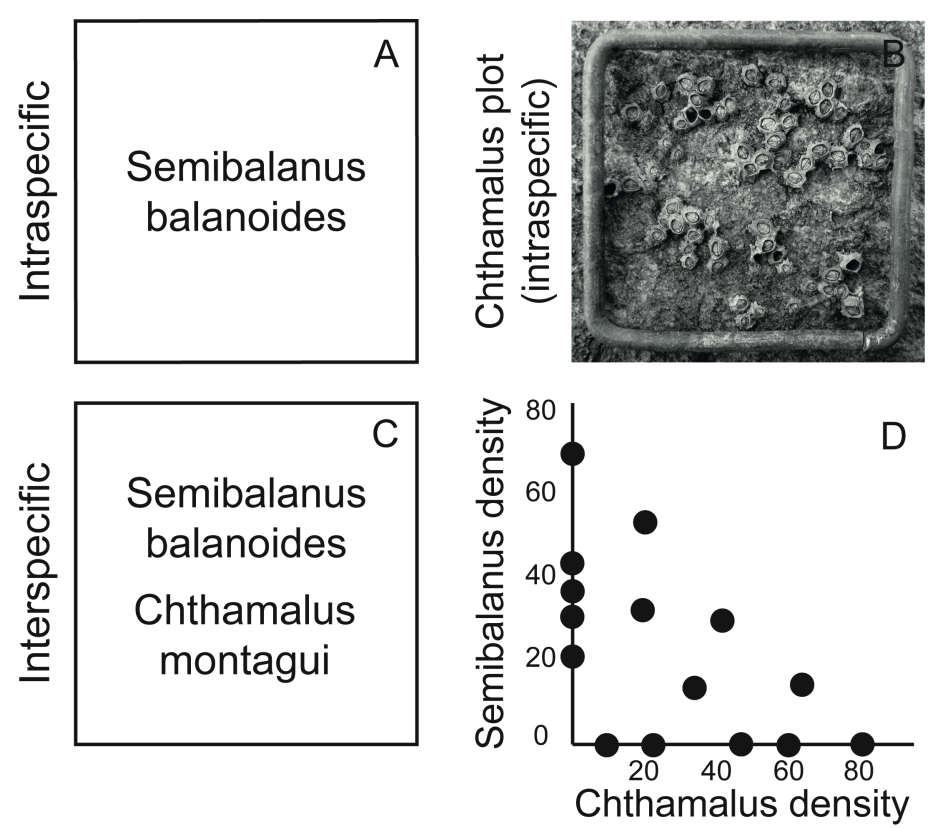

568

569

Fig. 2 
Intra and Interspecific competition

570

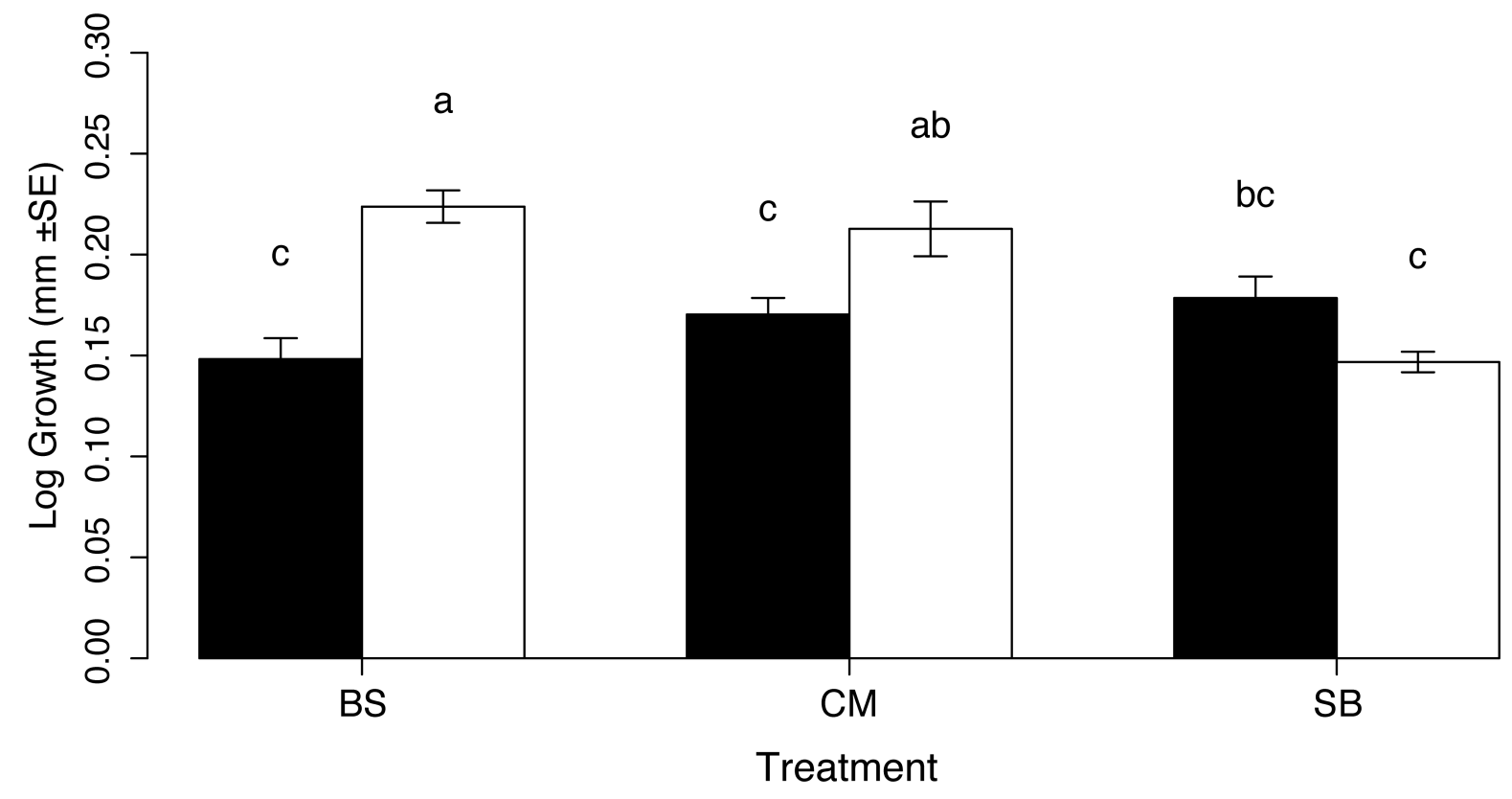

571

$572 \quad$ Fig. 3

573 
Intra and Interspecific competition

574

575

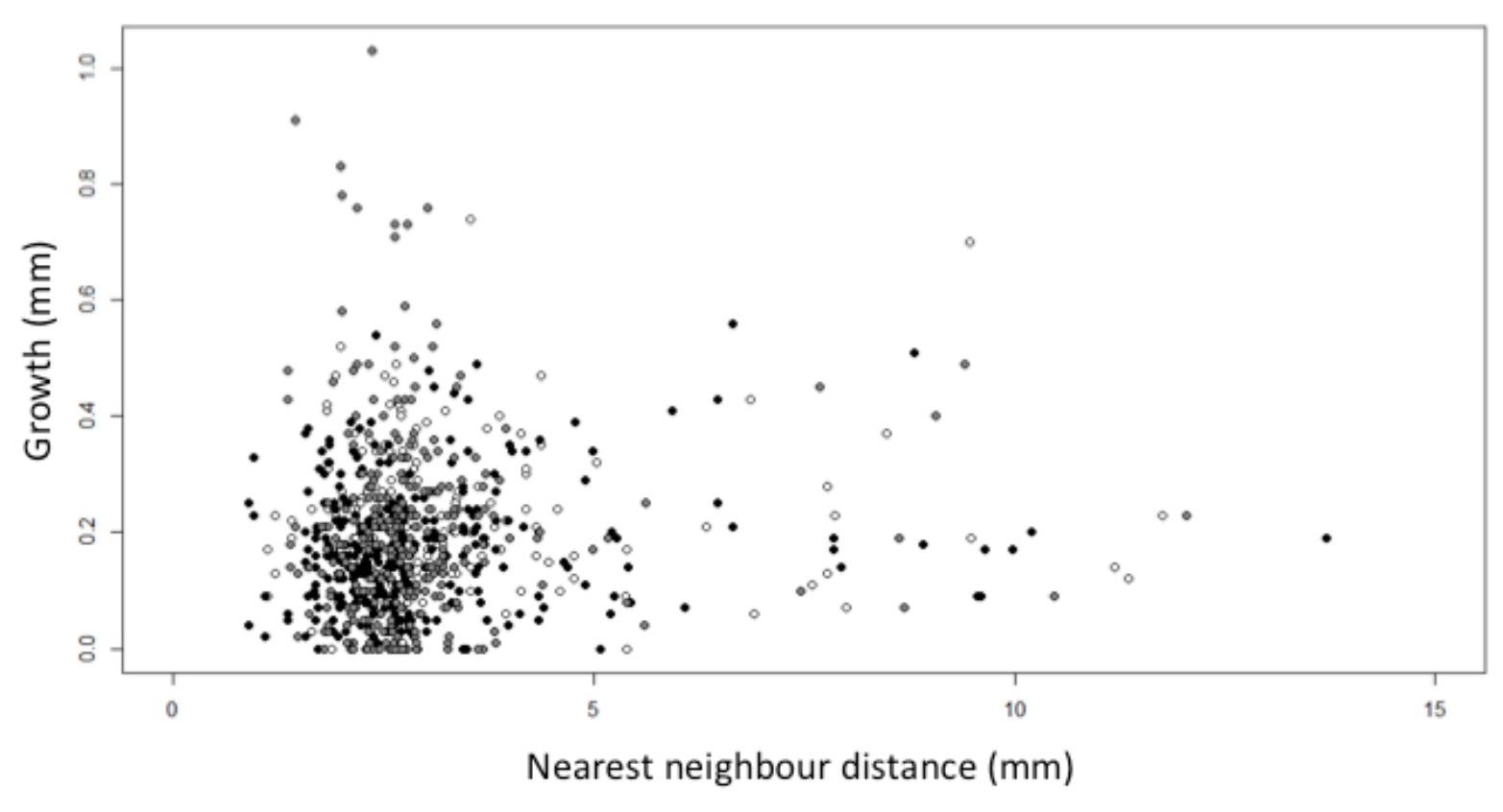

576

$577 \quad$ Fig. 4 
Intra and Interspecific competition

578

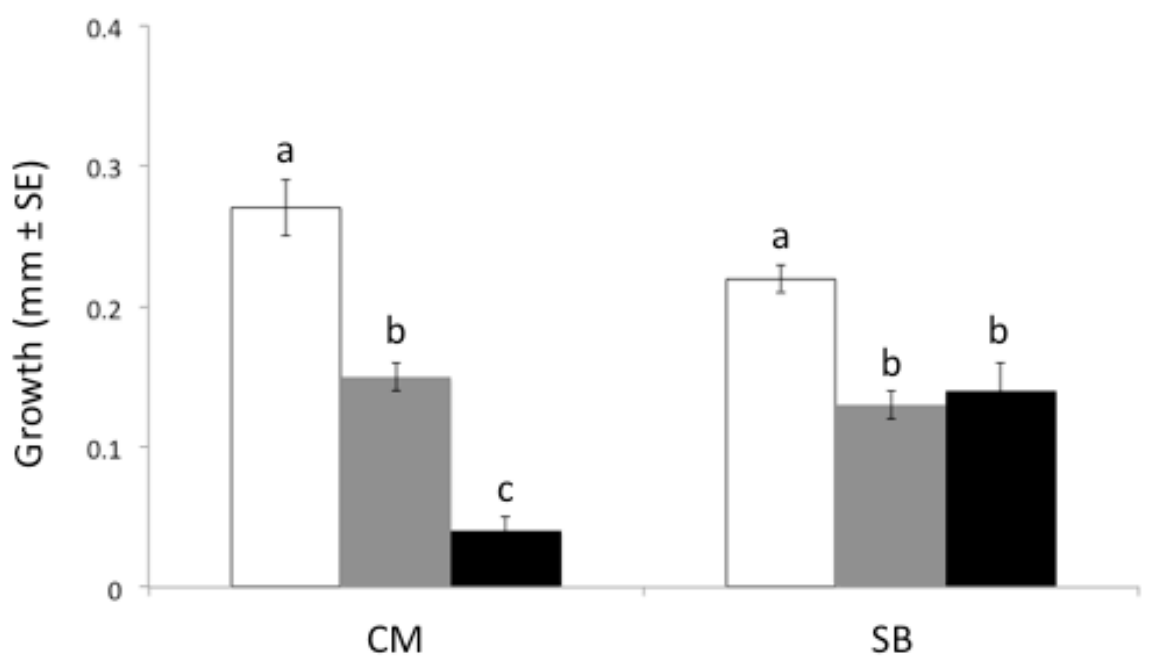

579

$580 \quad$ Fig. 5 
Intra and Interspecific competition

581

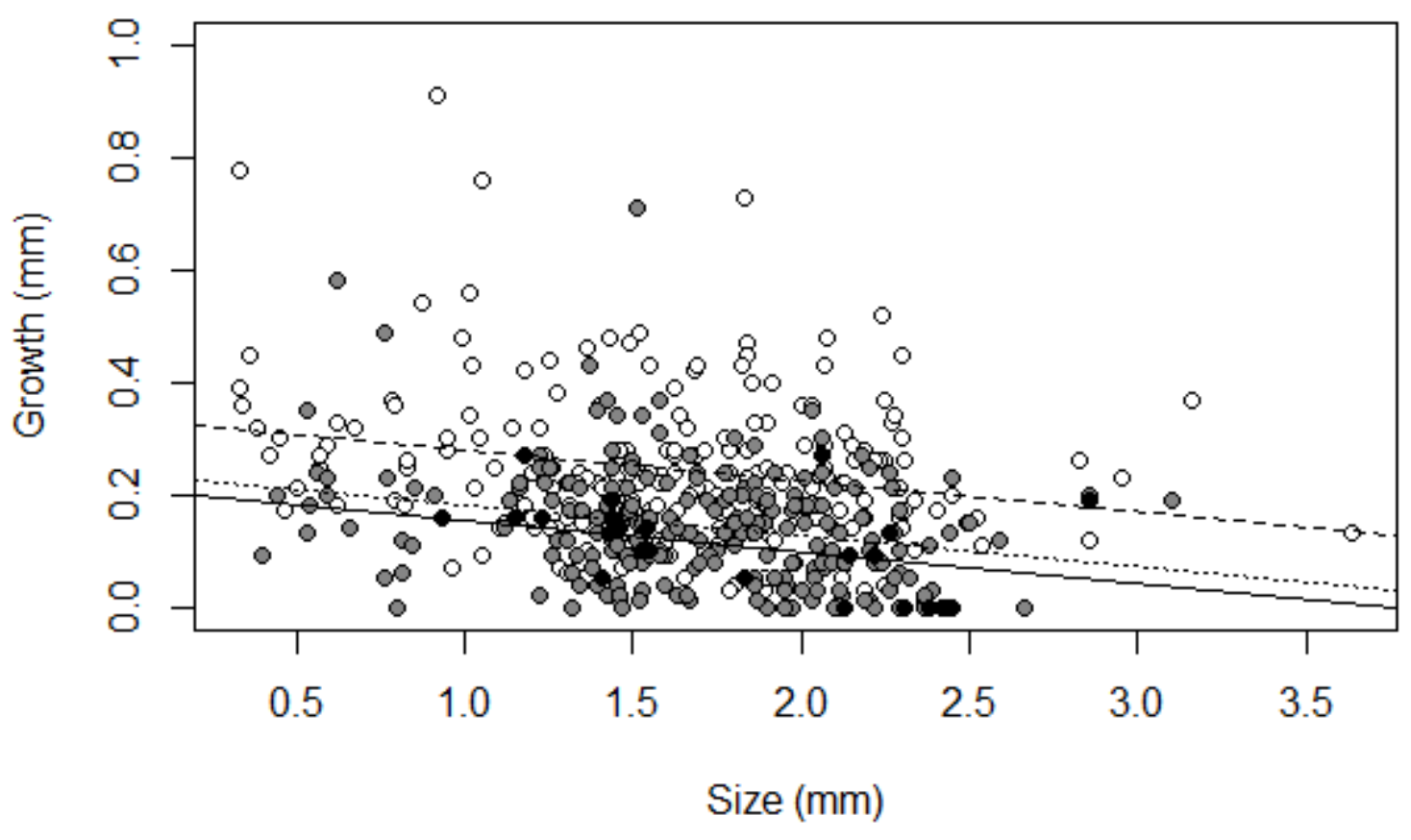

$583 \quad$ Fig. 6 
Intra and Interspecific competition

584

585

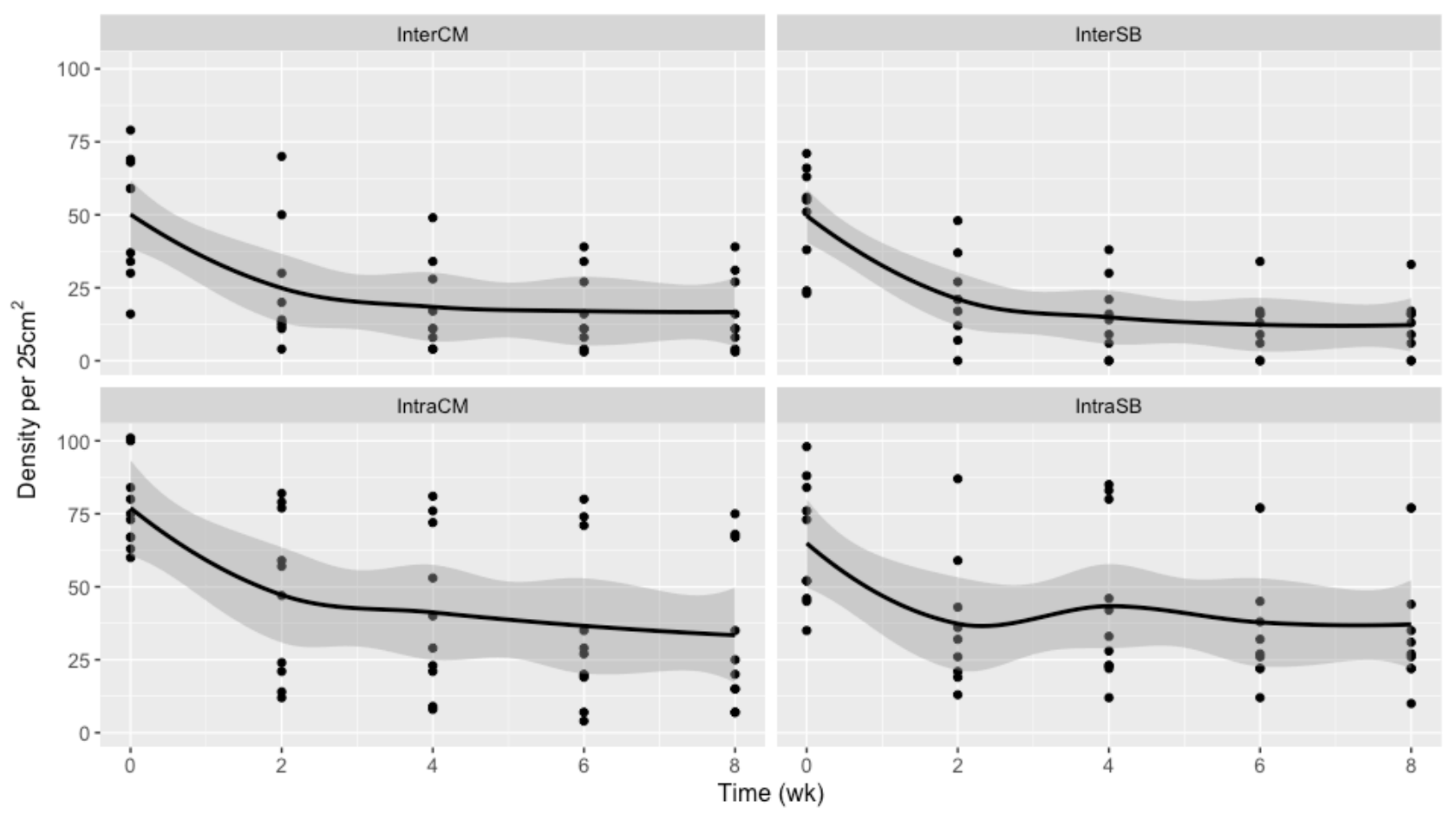

$586 \quad$ Fig. 7 
Intra and Interspecific competition

587

588

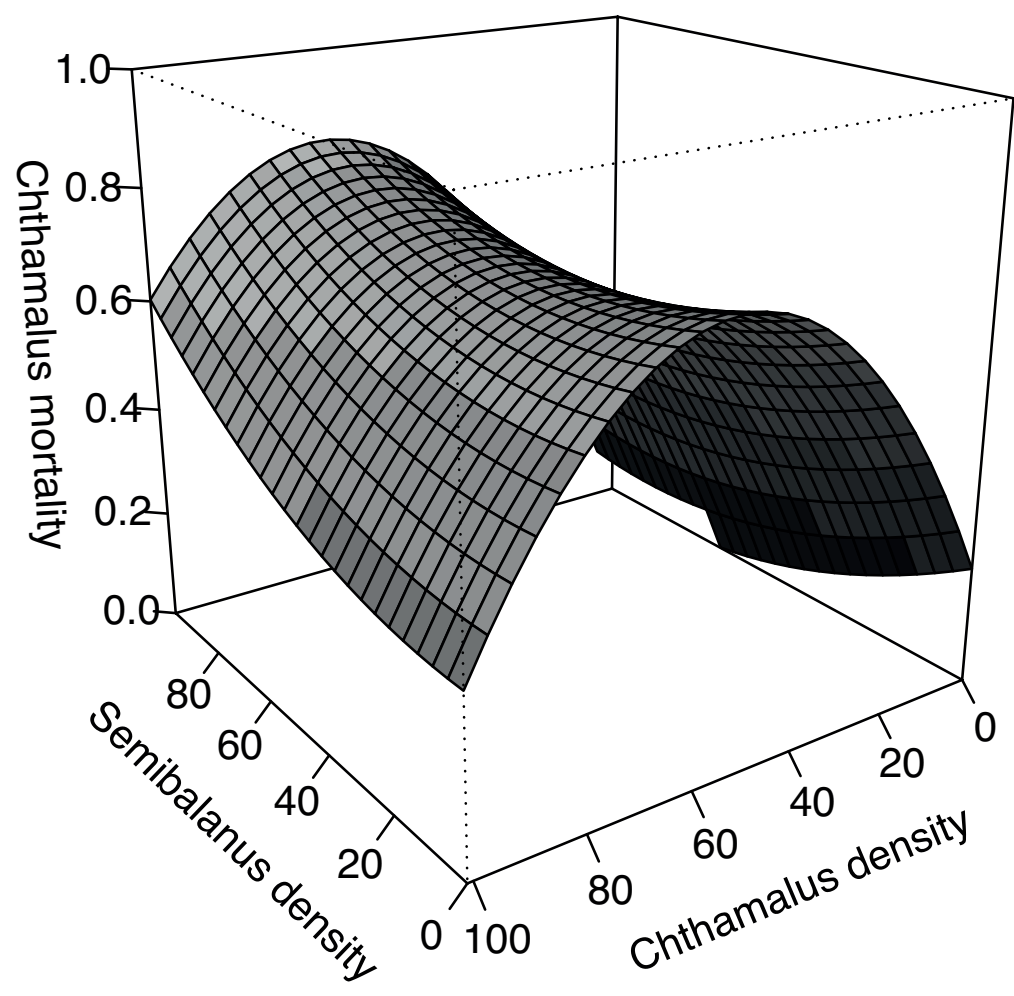

589

Fig. 8

590 